\title{
Assessing Diaphragmatic Function
}

\author{
Tom Schepens, Samira Fard, and Ewan C Goligher
}

\author{
Introduction \\ Respiratory Muscle Physiology \\ Causes of Diaphragm Weakness in the ICU \\ Monitoring Diaphragm Function and Activity \\ Respiratory System Pressures \\ Diaphragm EMG \\ Ultrasound \\ Balancing Over- and Underassistance \\ Summary
}

\begin{abstract}
The diaphragm is vulnerable to injury during mechanical ventilation, and diaphragm dysfunction is both a marker of severity of illness and a predictor of poor patient outcome in the ICU. A combination of factors can result in diaphragm weakness. Both insufficient and excessive diaphragmatic contractile effort can cause atrophy or injury, and recent evidence suggests that targeting an appropriate amount of diaphragm activity during mechanical ventilation has the potential to mitigate diaphragm dysfunction. Several monitoring tools can be used to assess diaphragm activity and function during mechanical ventilation, including pressure-derived parameters, electromyography, and ultrasound. This review details these techniques and presents the rationale for a diaphragm-protective ventilation strategy. Key words: diaphragm; respiratory muscles; muscle weakness; intensive care; diagnostic techniques; respiratory system; diaphragm dysfunction; effort-induced lung injury. [Respir Care 2020;65(6):807-819. (C) 2020 Daedalus Enterprises]
\end{abstract}

\section{Introduction}

Patients who are admitted to an ICU frequently exhibit muscle weakness, and the respiratory muscles are often affected. ${ }^{1}$ The diaphragm is the primary inspiratory muscle, and diaphragm dysfunction is both a marker of severity of illness and a predictor of poor patient outcome in the ICU.

Dr Schepens is affiliated with the Department of Critical Care Medicine, Antwerp University Hospital, Antwerp, Belgium. Ms Fard is affiliated with the Department of Respiratory Therapy, University Health Network, Toronto, Canada. Dr Goligher is affiliated with the Interdepartmental Division of Critical Care Medicine, University of Toronto, Toronto, Canada. Dr Goligher is affiliated with the Department of Medicine, Division of Respirology, University Health Network, Toronto, Canada.

Dr Schepens is supported in part by the European Respiratory Society, Fellowship STRF October 2018. Dr Goligher is supported by an Early Career Investigator Award from the Canadian Institutes of Health
There is a clear association between diaphragm dysfunction and an increased risk of mortality or prolonged mechanical ventilation. ${ }^{1-6}$ Factors related to both critical illness and ICU interventions are at the root of this problem. ${ }^{7}$ Mechanical ventilation is associated with diaphragm injury through a variety of mechanisms referred to as

\footnotetext{
Research, and he has disclosed a relationship with Getinge. Ms Fard has disclosed no conflicts of interest.

Dr Goligher presented a version of this paper at the 58th RESPIRATORY CARE Journal Conference, held June 10-11, 2019, in St Petersburg, Florida.

Correspondence: Ewan C Goligher MD PhD, Toronto General Hospital, 585 University Ave, Peter Munk Building, 11th Floor, Room 192, Toronto, Ontario, Canada M5G 2N2. E-mail: ewan.goligher@utoronto.ca.
}

DOI: $10.4187 /$ respcare.07410 


\section{Assessing Diaphragmatic FunCtion}
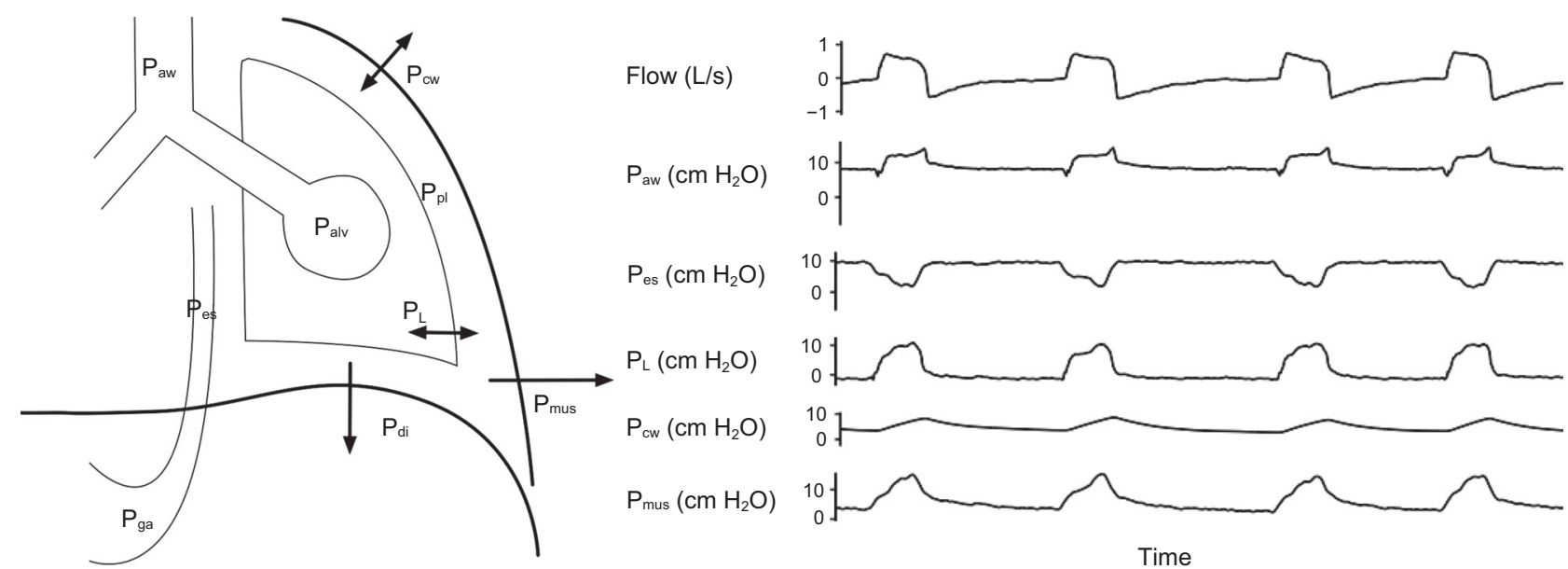

Fig. 1. Pressure model of the respiratory system. The locations of relevant pressures are depicted on the left. Typical tracings of respiratory pressures under assisted mechanical ventilation are shown on the right. $P_{p l}$ is estimated with esophageal manometry. The respiratory $P_{\text {mus }}$ is computed as the difference between observed $P_{c w}$ and $\Delta P_{e s} . P_{c w}$ is estimated as the product of tidal volume and chest wall elastance measured during passive ventilation. $P_{a l v}=$ alveolar pressure; $P_{a w}=$ airway pressure; $P_{c w}=$ chest wall elastic recoil pressure; $P_{e s}=$ esophageal pressure; $P_{g a}=$ gastric pressure; $P_{L}=$ transpulmonary pressure $\left(P_{a w}-P_{e s}\right) ; P_{\text {mus }}=$ respiratory muscle pressure; $P_{p l}=$ pleural pressure. Adapted from Reference 19.

myotrauma. ${ }^{8}$ The presence of either insufficient or excessive diaphragmatic contractile effort plays a central role in this process. In addition, vigorous diaphragmatic contractions also can result in lung injury. ${ }^{9-11}$ Recent evidence suggests that maintaining appropriate diaphragm activity during mechanical ventilation has the potential to prevent injury to the diaphragm. ${ }^{6}$ These observations have drawn greater attention to the importance of diaphragm monitoring in the ICU.

Several clinical monitoring tools are available to assess diaphragm activity and function, including various respiratory pressure measurements, electromyography (EMG), and ultrasound. This paper briefly discusses the impact of critical illness on the diaphragm, with an emphasis on the effects of mechanical ventilation and diaphragm activity, and details the effect of diaphragm dysfunction on outcome. It will then discuss the relevant techniques for monitoring diaphragm function, with special reference to their application in mechanically ventilated patients.

\section{Respiratory Muscle Physiology}

The diaphragm is a thin, dome-shaped muscle that inserts into the lower ribs, the xiphoid process, and the lumbar vertebrae, separating the thoracic and abdominal cavities. During inspiration, shortening of diaphragm muscle fibers results in a piston-like action, decreasing intrapleural pressure, drawing the lungs downwards, and increasing intraabdominal pressure. The force generated by the diaphragm is quantified by the transdiaphragmatic pressure $\left(\mathrm{P}_{\mathrm{di}}\right)$, which is the pressure gradient generated between the thoracic and abdominal cavities during diaphragm contraction.
It is calculated from the difference between the pressure in the stomach (gastric pressure, $\mathrm{P}_{\mathrm{ga}}$ ) and the esophageal pressure $\left(\mathrm{P}_{\mathrm{es}}\right.$, as a substitute for intrapleural pressure $)$ : $\mathrm{P}_{\mathrm{di}}=$ $\mathrm{P}_{\mathrm{ga}}-\mathrm{P}_{\mathrm{es} \cdot}{ }^{12-14}$ Decreasing pleural pressure generates a pressure gradient that drives flow and volume into the lungs, known as the transpulmonary pressure. The transpulmonary pressure is computed as the difference between airway pressure $\left(\mathrm{P}_{\mathrm{aw}}\right)$ and $\mathrm{P}_{\mathrm{es}}\left(\mathrm{ie}, \mathrm{P}_{\mathrm{aw}}-\mathrm{P}_{\mathrm{es}}\right)$. Of note, even though the $P_{e s}$ is closely related to the pleural pressure, the pleural pressure varies over the lung surface due to the effects of gravity and regional mechanics. ${ }^{15}$ This transpulmonary pressure drives alveolar ventilation and reflects the stress and strain applied to the lung by the respiratory muscles (and the ventilator).

Accessory respiratory muscles include the external intercostal, scalene, and sternocleidomastoid muscles. The external intercostal muscles pull the ribs upward and forward, increasing the lateral and anteroposterior diameters of the thorax. The scalene muscles elevate the first 2 ribs, and the sternocleidomastoids raise the sternum.

Exhalation is largely a passive process, except under conditions of increased respiratory load. ${ }^{16}$ When the workload increases, the abdominal muscles contract during expiration, with an initial recruitment of transversus abdominis muscle and subsequent recruitment of the other abdominal muscles. ${ }^{17}$ Expiratory abdominal muscle contraction enhances inspiratory diaphragm performance (through its lengthtension relationship) and spring loads the thoracic cage to expand when the abdominal muscles relax, assisting with the inspiratory work of breathing. ${ }^{18}$ The work of breathing during heavy loads is thus redistributed to accessory inspiratory muscles, abdominal muscles, and the diaphragm. 


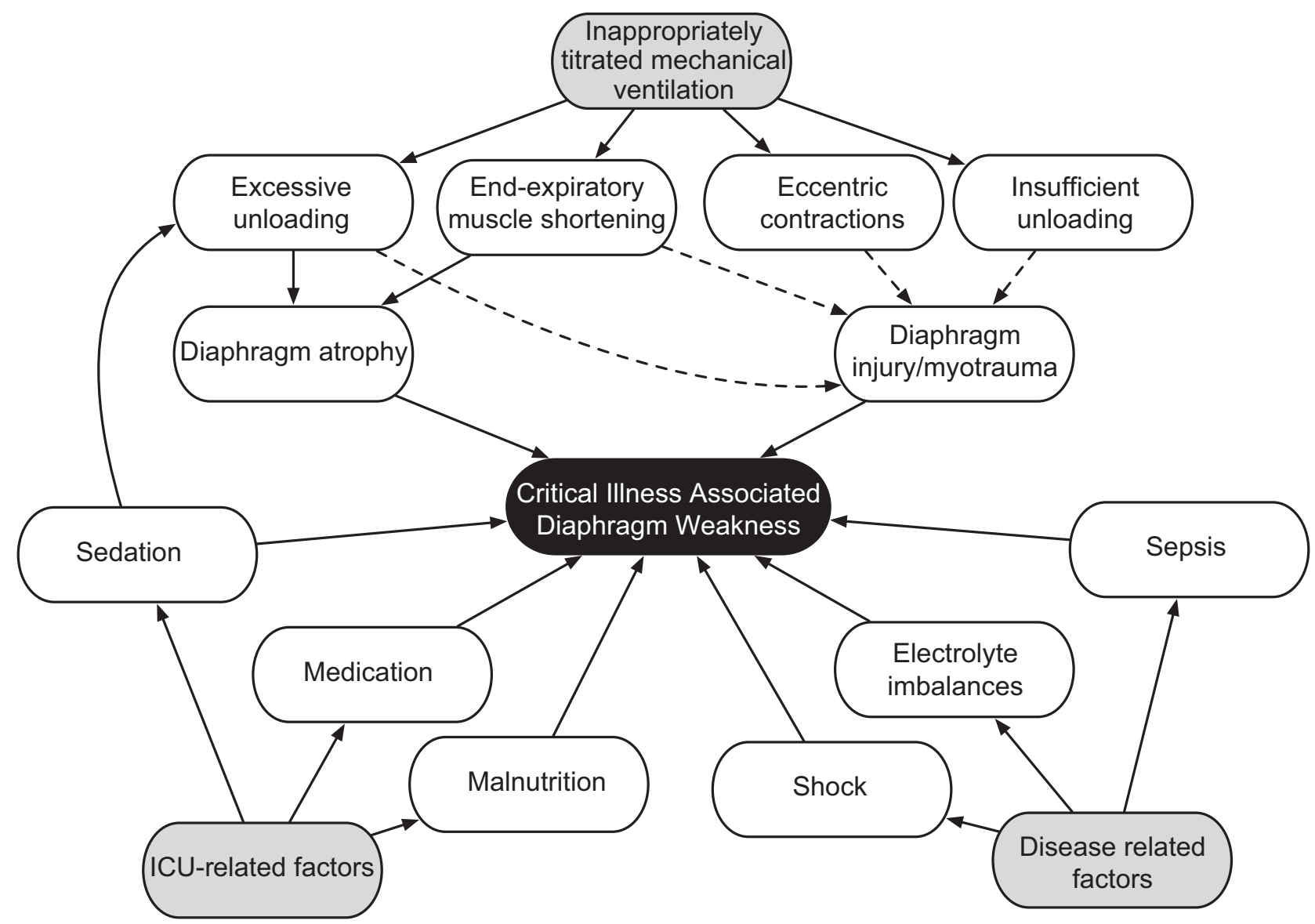

Fig. 2. Schematic illustration of the mechanisms involved in the occurrence of critical illness-associated diaphragm weakness. Dashed lines represent uncertain causation; solid lines represent established causation. Adapted from Reference 7.

Figure 1 summarizes the action of respiratory muscles and pressure relationships.

\section{Causes of Diaphragm Weakness in the ICU}

The causes and mechanisms leading to the observed weakness of the diaphragm in ventilated patients in the ICU have been extensively studied. We now know that there are multiple intertwined factors related to critical illness, ICU stay and therapies, and mechanical ventilation itself that are causing this weakness. The combination of these mechanisms causing diaphragm injury and weakness in the ICU is now called critical illness-associated diaphragm weakness. The precise mechanisms are thoroughly detailed in a recent review by Dres et $\mathrm{al}^{7}$ and summarized in Figure 2 .

Of specific interest for this article are the mechanisms of ventilator myotrauma, which are the deleterious effects of mechanical ventilation on diaphragm structure and function. Up to 4 distinct forms of myotrauma might occur during ventilation: ventilator overassistance, ventilator underassistance, eccentric (pliometric) diaphragm contractions, and excessive end-expiratory shortening. Interestingly, these mechanisms have the potential to be targeted by specific ventilation strategies, potentially mitigating the occurrence or severity of diaphragm myotrauma.

Overassistance myotrauma refers to the diaphragm atrophy resulting from excessive unloading of the respiratory muscles. ${ }^{20-24}$ This form of injury is well documented in the clinical setting. It affects approximately $50 \%$ of ventilated patients and can be mitigated by preserving some degree of muscle activity during mechanical ventilation. ${ }^{20,25-27}$

Underassistance myotrauma develops when respiratory effort is excessive because of insufficient unloading. ${ }^{28}$ Experimental and clinical studies have demonstrated sarcomere disruption, tissue inflammation, and muscle fatigue. ${ }^{29-31}$ Sepsis renders the muscle tissue particularly susceptible to this form of injury. ${ }^{32}$ The observation that diaphragm thickness increases over time in some ventilated patients (in association with elevated respiratory effort) may reflect this edema and injury. ${ }^{6}$

Eccentric diaphragm contractions developing during muscle fiber lengthening, that is, during the ventilator's expiratory phase, can also cause injury (ie, eccentric myotrauma). 
Eccentric loading is considerably more injurious than concentric loading. This type of myotrauma can be the result of increased postinspiratory diaphragm activity in the expiratory phase (ie, expiratory braking), patient-ventilator asynchrony (particularly reverse-triggering), or even excessive accessory respiratory muscle activity moving the diaphragm cranially during inspiration. ${ }^{33,34}$

Preliminary evidence also suggests the possibility that prolonged shortening of the diaphragm from elevated end-expiratory pressure may cause muscle fiber dropout and may allow longitudinal atrophy. ${ }^{35}$ Abruptly decreasing PEEP may then put the diaphragm in a disadvantageous length-tension relationship at the beginning of inspiration. ${ }^{36}$ The clinical relevance of this phenomenon is uncertain.

This brief summary of the mechanisms of diaphragm myotrauma suggests that routine monitoring of diaphragm activity and function might help clinicians prevent or mitigate myotrauma, potentially improving clinical outcomes.

\section{Monitoring Diaphragm Function and Activity}

A range of techniques are available to monitor the diaphragm. Depending on the conditions under which they are measured, these techniques can be used to quantify either function (ie, force-generating capacity) or muscular contractile activity. Most tests of muscle function require a maximum volitional contractile effort from the patient. Some parameters actually reflect the performance of the respiratory system as a whole, not just the diaphragm. We will discuss the relevant techniques with special reference to their application in mechanically ventilated patients. These are summarized in Table 1.

\section{Respiratory System Pressures}

Several techniques measure the pressures generated by the respiratory system as a whole or by the diaphragm alone (Table 1). The maximum inspiratory pressure $\left(\mathrm{P}_{\mathrm{Imax}}\right)$ can be measured at the airway while the patient makes a maximum inspiratory effort against a closed airway; this is frequently used as a test of respiratory muscle function. ${ }^{37} \mathrm{~A} 1$ way valve should be applied so that the patient can exhale but not inhale, thus minimizing lung volume to optimize the length-tension relationship of the diaphragm and maximize force generation. When both $\mathrm{P}_{\mathrm{ga}}$ and $\mathrm{P}_{\mathrm{es}}$ are recorded during this effort, maximum $\mathrm{P}_{\mathrm{di}}$ can be calculated to specifically evaluate the strength of the diaphragm. A related parameter is the pressure generated by all respiratory muscles $\left(\mathrm{P}_{\mathrm{mus}}\right)$. By definition, $\mathrm{P}_{\mathrm{mus}}=\left(\mathrm{V}_{\mathrm{T}} \times \mathrm{E}_{\mathrm{cw}}\right)-\Delta \mathrm{P}_{\mathrm{PL}}$, where $\mathrm{V}_{\mathrm{T}}$ is the tidal volume, $\Delta-\mathrm{P}_{\mathrm{PL}}$ is the pleural pressure swing represented by $\Delta-\mathrm{P}_{\mathrm{es}}$, and $\mathrm{E}_{\mathrm{cw}}$ is the chest wall elastance. When the airway is occluded, $\mathrm{P}_{\text {mus }}$ is equal to $\Delta \mathrm{P}_{\mathrm{es}}$ and hence to $\Delta \mathrm{P}_{\mathrm{aw}}$.
With these techniques, it is critical to make sure that the patient is exerting maximum effort. This dependence on effort is the primary drawback of all volitional function tests. To circumvent this shortcoming, different strategies have been implemented. By stimulating the phrenic nerves with a magnetic or electric pulse (or twitch) while the patient is relaxed at end-expiration, a brief diaphragm contraction of standard magnitude is induced, independent of the patient's effort. ${ }^{37}$ Despite its technical challenges, this technique is the accepted standard for measuring diaphragm function in ventilated patients. ${ }^{42}$ To obtain accurate values, a supramaximal stimulation of the phrenic nerves is needed, and positioning of the magnetic coils must be very precise. Similarly, twitch $\mathrm{P}_{\mathrm{aw}}$ can be recorded to provide a close estimate of twitch $\mathrm{P}_{\mathrm{di}}$ in ventilated patients. ${ }^{42,43}$ Reference cutoff values defining diaphragm weakness are available and are summarized in Table 1. Some have proposed lower cutoff values for twitch $\mathrm{P}_{\mathrm{aw}}$ for defining dysfunction in an ICU setting, based on the possibility of these values to better predict weaning outcome. ${ }^{44}$

An alternative strategy to obtain maximum volitional effort for a functional measurement is to apply a 20-s airway occlusion with a 1-way valve (Marini maneuver), allowing for expiration but not inspiration. ${ }^{45}$ The pressure obtained with this maneuver corresponds closely to the pressure obtained when patients are coached to breathe at maximum effort, provided that respiratory drive is adequate at rest (ie, $\mathrm{P}_{0.1}>2 \mathrm{~cm} \mathrm{H}_{2} \mathrm{O}$ ).

Another technique to measure respiratory muscle strength in nonintubated patients is the sniff nasal inspiratory pressure (SNIP). Sniffing is an intuitive subconscious maneuver that elicits maximal diaphragmatic and respiratory muscle activation. Like the previously mentioned parameters, $\mathrm{P}_{\mathrm{es}}$ and transdiaphragmatic pressures can also be recorded during sniffing.

If the pressure is obtained during a tidal breath, the recorded pressure quantifies the effort exerted by the respiratory muscles or diaphragm. During inspiration, a negative deflection in esophageal pressures signifies respiratory muscle contraction. Figure 3 shows a sample of high and low inspiratory effort, documented with $\mathrm{P}_{\mathrm{es}}$ and $\mathrm{P}_{\mathrm{aw}}$ tracings. Small amounts of diaphragm activity may go unnoticed by only looking at the $\mathrm{P}_{\mathrm{es}}$ curve (ie, the amount of effort counterbalanced by chest wall recoil pressure, see Fig. 1), which may be detected with EMG monitoring. ${ }^{46}$

The airway occlusion pressure $\left(\mathrm{P}_{0.1}\right)$, which is the pressure developed in the occluded airway $100 \mathrm{~ms}$ after the onset of inspiration, is an old parameter that may have a value in the assessment of a patient's respiratory drive. ${ }^{47} \mathrm{It}$ can be obtained easily on most ventilators, and it is reliable in the setting of respiratory muscle weakness. ${ }^{48}$ It correlates well with work of breathing (WOB) and the pressuretime product (PTP), 2 parameters that assess respiratory 


\section{Assessing Diaphragmatic Function}

Table 1. Pressure-Based Monitoring Tools, EMG, and Ultrasound Parameters to Evaluate Diaphragm and Respiratory System Activity and Function

\begin{tabular}{|c|c|c|c|c|}
\hline & Activity & Function & Cutoff Defining Weakness & Reference \\
\hline \multicolumn{5}{|c|}{ Pressure-derived parameters } \\
\hline \multirow[t]{6}{*}{ Respiratory system } & & $\mathrm{P}_{\operatorname{Imax}}$ & $\begin{array}{l}\geq 80 \mathrm{~cm} \mathrm{H}_{2} \mathrm{O} \text { in men, } \geq 70 \mathrm{~cm} \mathrm{H}_{2} \mathrm{O} \text { in } \\
\text { women excludes significant weakness }\end{array}$ & Laveneziana et $\mathrm{al}^{37}$ \\
\hline & & SNIP & $\begin{array}{r}\geq 80 \mathrm{~cm} \mathrm{H}_{2} \mathrm{O} \text { in men, } \geq 70 \mathrm{~cm} \mathrm{H}_{2} \mathrm{O} \text { in } \\
\text { women excludes significant weakness }\end{array}$ & Laveneziana et $\mathrm{al}^{37}$ \\
\hline & $\mathrm{P}_{0.1}$ & & & \\
\hline & WOB, PTP, TT & & & \\
\hline & $\mathrm{P}_{\text {mus }}$ & & & \\
\hline & $\mathrm{P}_{\mathrm{es}}$ & & & \\
\hline \multirow[t]{5}{*}{ Diaphragm } & $\mathrm{P}_{\mathrm{di}}$ & & & \\
\hline & & Maximum $\mathrm{P}_{\mathrm{di}}$ & $\begin{aligned} \geq & 80 \mathrm{~cm} \mathrm{H}_{2} \mathrm{O} \text { in men, } \geq 70 \mathrm{~cm} \mathrm{H}_{2} \mathrm{O} \text { in } \\
& \text { women excludes significant weakness }\end{aligned}$ & Laveneziana et $\mathrm{al}^{37}$ \\
\hline & & Twitch $\mathrm{P}_{\mathrm{di}}$ & $<18 \mathrm{~cm} \mathrm{H}_{2} \mathrm{O}$ & Steier et $\mathrm{al}^{38}$ \\
\hline & & Twitch $\mathrm{P}_{\mathrm{aw}}$ & $<11 \mathrm{~cm} \mathrm{H}_{2} \mathrm{O}$ & Demoule et $\mathrm{al}^{39}$ \\
\hline & & $\mathrm{P}_{\mathrm{di}}($ sniff test $)$ & $\begin{array}{l}\geq 80 \mathrm{~cm} \mathrm{H}_{2} \mathrm{O} \text { in men, } \geq 70 \mathrm{~cm} \mathrm{H}_{2} \mathrm{O} \text { in } \\
\text { women excludes significant weakness }\end{array}$ & Laveneziana et $\mathrm{al}^{37}$ \\
\hline \multirow[t]{4}{*}{ Electromyography } & PVBC & & & \\
\hline & Peak $\mathrm{EA}_{\mathrm{di}}$ & & & \\
\hline & & Maximum $\mathrm{EA}_{\mathrm{di}}$ & None & \\
\hline & & Neuromuscular efficiency & None & \\
\hline \multirow[t]{5}{*}{ Ultrasound } & $\mathrm{TF}_{\mathrm{di}}$ & & & \\
\hline & & Maximum $\mathrm{TF}_{\mathrm{di}}$ & $<20 \%$ & $\begin{array}{l}\text { Gottesman and } \\
\mathrm{McCool}^{40}\end{array}$ \\
\hline & $\mathrm{EX}_{\mathrm{di}}$ & $\mathrm{EX}_{\mathrm{di}}$ & $<1 \mathrm{~cm}$ & Kim et $\mathrm{al}^{4}$ \\
\hline & & Maximum $\mathrm{EX}_{\mathrm{di}}$ & $<3.6$ (female),$<4.7$ (male) & Boussuges et $\mathrm{a}^{41}$ \\
\hline & & Sniff $\mathrm{EX}_{\mathrm{di}}$ & $<1.6$ (female),$<1.8$ (male) & Boussuges et $\mathrm{a}^{41}$ \\
\hline
\end{tabular}

activity, so $\mathrm{P}_{0.1}$ can reliably demonstrate excessive effort during various modes of ventilation and during extracorporeal membrane oxygenation. ${ }^{49-52}$ Cutoff values indicating underassist have been proposed. Rittayamai and coworkers ${ }^{51}$ defined the optimal threshold of $\mathrm{P}_{0.1}$ at $3.5 \mathrm{~cm}$ $\mathrm{H}_{2} \mathrm{O}$ with a sensitivity of $92 \%$ and a specificity of $89 \%$ to detect underassist; others have set the optimal threshold for overassistance at $\leq 1.6 \mathrm{~cm} \mathrm{H}_{2} \mathrm{O}$.

The amplitude of swings in $\mathrm{P}_{\mathrm{di}}$ and $\mathrm{P}_{\mathrm{es}}$ do not fully reflect the amount of breathing effort a patient performs because the inspiratory time, frequency, and expiratory muscle activity are not taken into account. ${ }^{53}$ The PTP is the integral of the pressure developed by the respiratory muscles during contraction (ie, $\mathrm{P}_{\text {mus }}$ ) over time (specified as either per breath or per minute). When $\mathrm{P}_{\mathrm{di}}$ is measured, the specific PTP of the diaphragm can be quantified. Oxygen consumption by the respiratory muscles correlates well with the PTP, whereas it only weakly correlates with the mechanical WOB index mentioned above. ${ }^{54}$ This could be due to the fact that PTP takes the isometric phase of muscle contraction into account.
If PTP is normalized to $\mathrm{P}_{\mathrm{Imax}}$ and duty cycle, the resulting quantity can be used to assess the loadcapacity relationship of the respiratory muscles. This quantity is the tension-time index (TTI) and can be calculated as

$$
\frac{\text { Mean inspiratory pressure }}{\text { Maximum inspiratory pressure }} \times \frac{\text { Inspiratory Time }}{\text { Total Time }} .
$$

The TTI predicts whether a given respiratory load can be sustained for a long period of time. TTI values $>0.15$ predict impending respiratory failure because this respiratory muscle load cannot be sustained. ${ }^{55,56}$

\section{Diaphragm EMG}

Diaphragm EMG can be used to assess diaphragm activity. Either surface EMG for the costal diaphragm or esophageal recordings of the crural diaphragm can be used. Needle EMG studies are rarely used to monitor diaphragm activity for clinical monitoring, but they can be useful in 

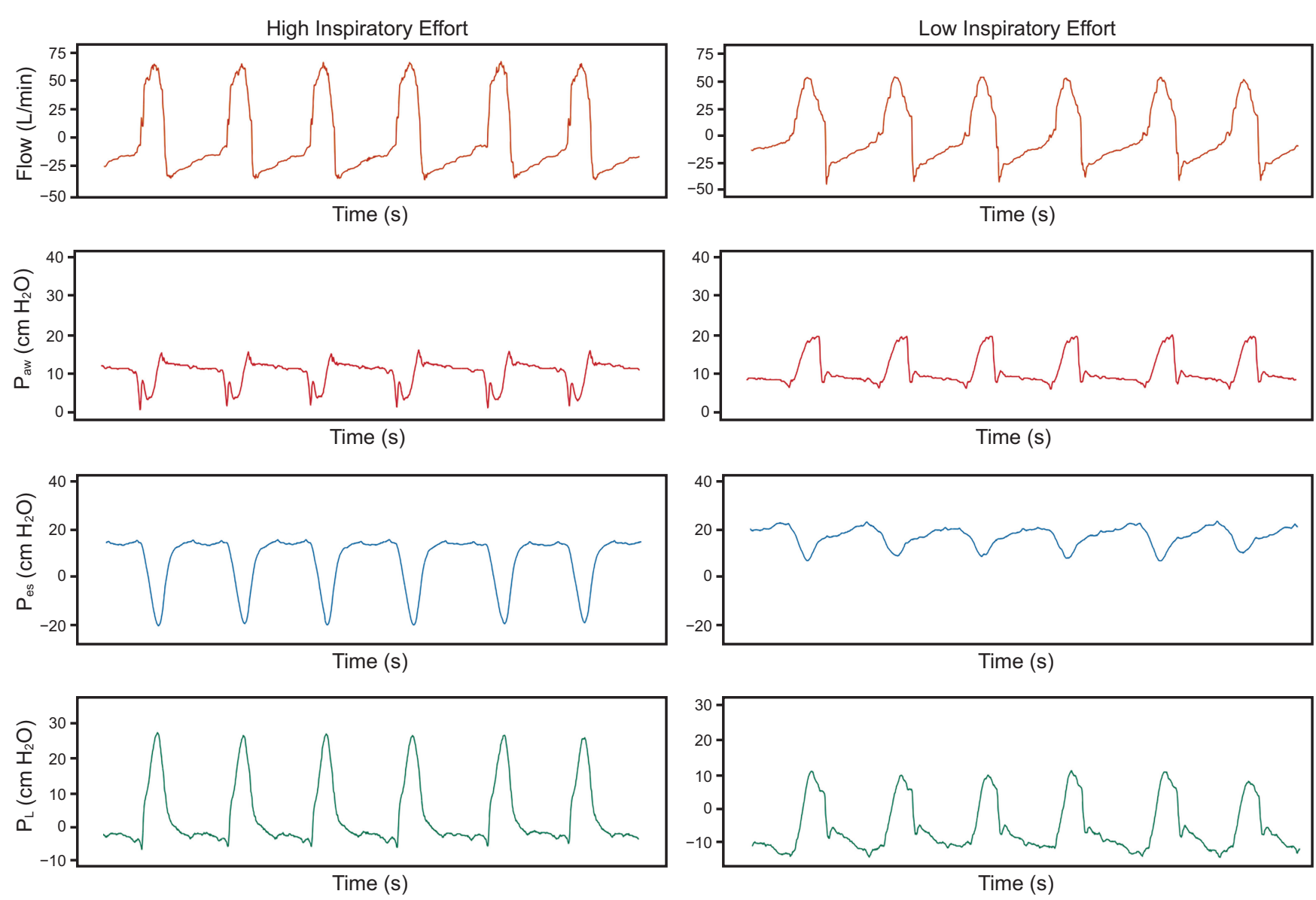

Fig. 3. Airway pressure $\left(P_{\text {aw }}\right)$, esophageal pressure $\left(P_{e s}\right)$, and transpulmonary pressure $\left(P_{\llcorner}\right)$tracings of a patient with high (left) and low (right) inspiratory effort. High effort is demonstrated by a large drop in $\mathrm{P}_{\mathrm{es}}$ during inspiration.

the assessment of neuropathy and myopathy. The EMGderived parameters are summarized in Table 1.

EMG provides the best clinically available representation of the integrated neural output of the brain's respiratory center; changes in EMG values are linearly correlated with changes in $\mathrm{CO}_{2}$ levels. ${ }^{52,57}$ A specialized nasogastric tube with electrodes positioned at the diaphragm can be used to measure the crural diaphragm electric activity $\left(\mathrm{EA}_{\mathrm{di}}\right)$. A specific mode of ventilation called neutrally adjusted ventilatory assist uses this measurement to synchronize diaphragm EMG with the ventilator. The peak of the $\mathrm{EA}_{\mathrm{di}}$ signals per breath and $\mathrm{EA}_{\mathrm{di}}$ values during maximum inspiratory effort can be recorded. Some elements need to be taken into account to understand the relationship between diaphragm EMG, respiratory drive, and diaphragm force. One of the elements is the neuromuscular efficiency, which is the relationship or coupling between $\mathrm{EA}_{\mathrm{di}}$ and $\mathrm{P}_{\mathrm{di}}$ (ie, the pressure generated by the diaphragm). By definition, the neuromuscular efficiency index is $\mathrm{P}_{\mathrm{di}} / \mathrm{EA}_{\mathrm{di}}\left(\mathrm{cm} \mathrm{H} \mathrm{H}_{2} \mathrm{O} / \mathrm{mcV}\right)$. This index is patient-specific and can change over time. ${ }^{58,59}$ As a result, neuromuscular efficiency can only be used to estimate the breathing effort and diaphragm function on an individual basis because reference values are nonexistent. ${ }^{58}$ In a study by Liu et al, ${ }^{60}$ subjects who passed a spontaneous breathing trial exhibited higher neuromuscular efficiency values than those who failed the spontaneous breathing trial.

\section{Ultrasound}

Diaphragm ultrasound has gained popularity in the last decade because it enables clinicians to directly and noninvasively assess diaphragm activity and function. The diaphragm can be visualized in 2 ways, either in the zone of apposition or via a subcostal anterior approach. There are excellent reviews on the technical details and validity of these techniques, summarized in Table $1 .^{61,62}$ When the diaphragm contracts and shortens, the muscle thickens, and this thickening can be visualized on ultrasound (Fig. 4). The increase in thickness during contraction (quantified as the thickening fraction) reflects diaphragm contractile activity and correlates with other parameters of diaphragm activity, like $\mathrm{EA}_{\mathrm{di}}$ and PTP. ${ }^{62,64}$ The maximum thickening fraction correlates with twitch $\mathrm{P}_{\mathrm{aw}}$ and 

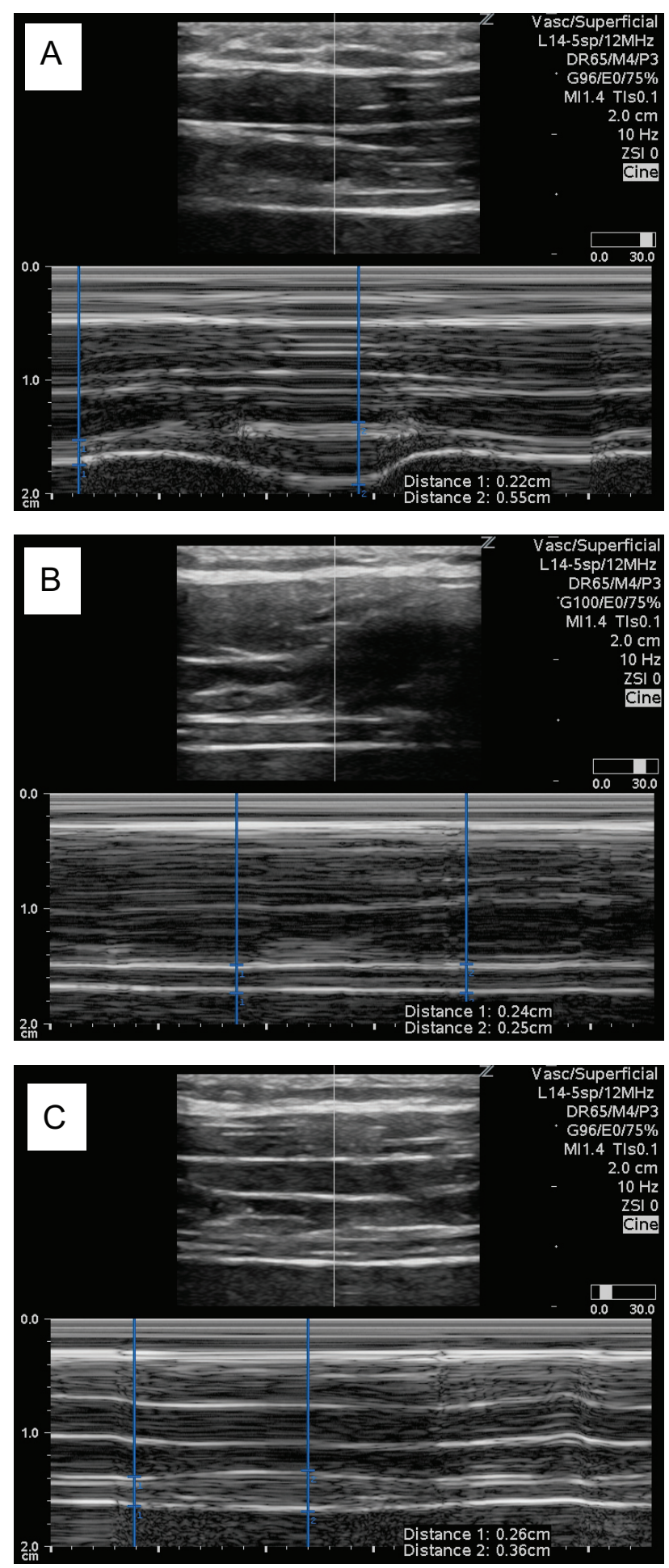

Fig. 4. M-mode ultrasound images of the diaphragm measured at the zone of apposition, and measurements of the thickness (blue vertical lines) during expiration (distance 1) and inspiration (distance 2). (A) Undersupport with a thickening fraction of $150 \%$ : ([0.55 $0.22 \mathrm{~cm}] \times 100) / 0.22 \mathrm{~cm}$. (B) Oversupport with a thickening fraction of $4 \%$ : $([0.25-0.24 \mathrm{~cm}] \times 100) / 0.24 \mathrm{~cm}$. (C) Adequate support with a thickening fraction of $38 \%$ : $([0.36-0.26 \mathrm{~cm}] \times 100) / 0.26 \mathrm{~cm}$. Reprinted from Reference 63, with permission. provides an estimate of diaphragm function. ${ }^{44,65,66}$ The technique can also be used to detect structural changes in the diaphragm during mechanical ventilation, such as diaphragm atrophy, load-induced injury, or recovery of muscle mass. ${ }^{6,20,23,67}$

As discussed earlier, a maximum inspiratory effort is required to assess diaphragm function (ie, maximum thickening fraction). A maximum inspiratory effort can be elicited by coaching or by the Marini maneuver (described above). However, because thickening results from muscular shortening, occluding the airway during the inspiratory effort can artefactually reduce thickening. Consequently, if a prolonged 20-s occlusion is applied to maximize inspiratory effort, maximal thickening should be measured only once the occlusion is released (but shortly after so that respiratory effort is still elevated).

Diaphragm excursion (motion) can be quantified when looking at the diaphragm subcostally (Fig. 5). These measurements provide a well-validated method of assessing diaphragm function. Importantly, interpretation of the result is only possible during unassisted breaths because downward displacement during assisted breaths could be a result of passive lung inflation by the ventilator. Therefore, the excursion cannot be used to monitor effort during mechanical ventilation. Diaphragm weakness will result in reduced caudal excursion, and paresis will often result in cranial (paradoxical) excursion during inspiration. ${ }^{67}$ Vigorous accessory respiratory muscle activity moving the diaphragm cranially during inspiration could theoretically give falsely low values for this parameter.$^{34}$ Cutoff values for the diagnosis of diaphragm dysfunction using these techniques are summarized in Table 1 .

\section{Balancing Over- and Underassistance}

There is uncertainty about the optimum range of diaphragm activity during mechanical ventilation, but the avoidance of excessive activity when possible appears to be supported by recent evidence. Several parameter values have been proposed to demonstrate underassistance, including PTP and WOB. Table 2 summarizes the possible monitoring techniques to assess patient and ventilator breath contribution and to balance over- and underassistance.

\section{Summary}

The diaphragm is vulnerable to injury during mechanical ventilation, and a range of factors can impact its function. Among these factors, the effects of mechanical ventilation require close attention as they are potentially avoidable. Several mechanisms link mechanical ventilation with diaphragm injury, including excessive and insufficient respiratory support, which can lead to very 


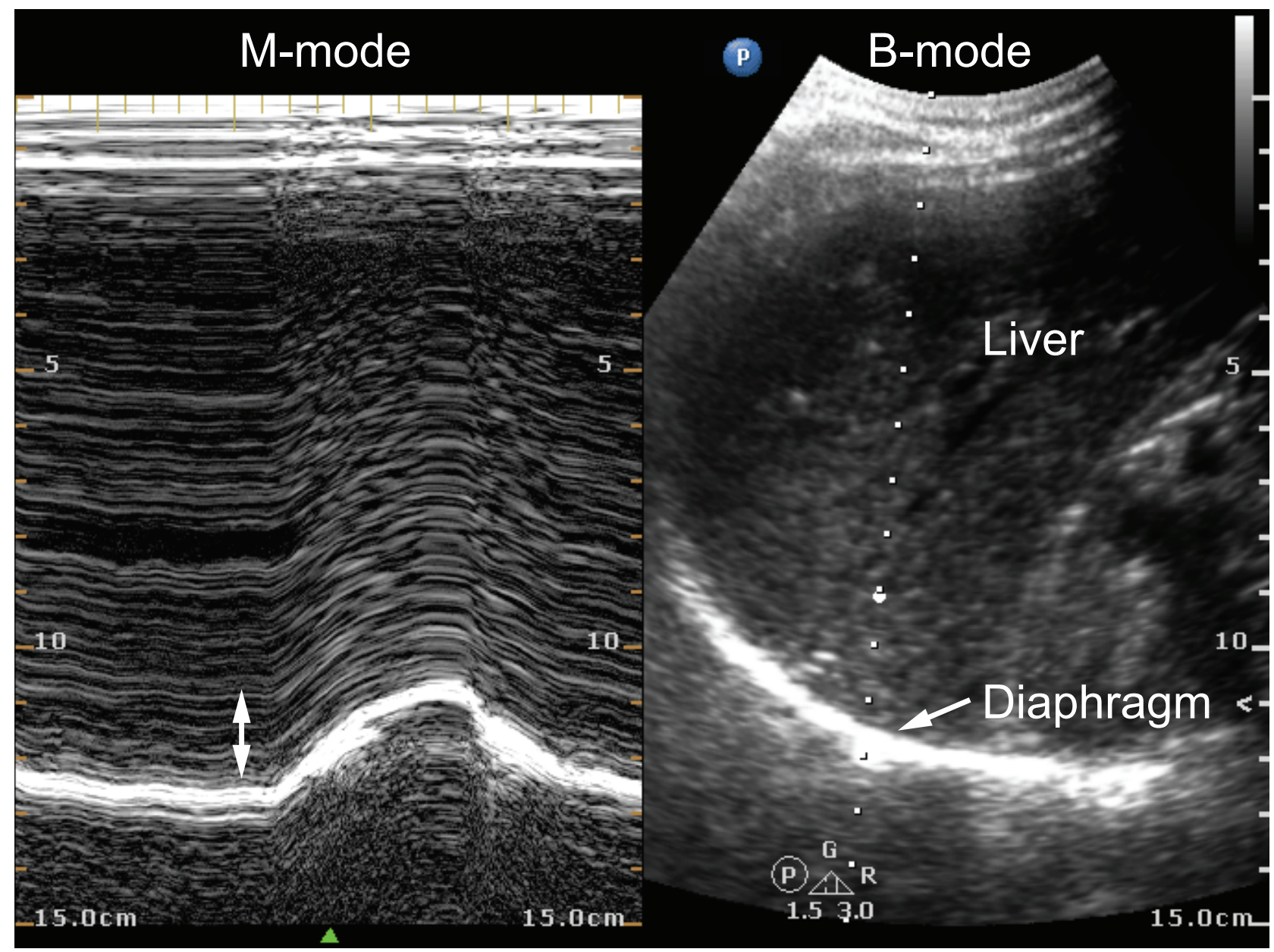

Fig. 5. B-mode (right) and M-mode (left) ultrasound images of the diaphragm with a probe positioned subcostally. A downward diaphragm excursion during inspiration (ie, towards the ultrasound probe) is visible. Reprinted from Reference 68, with permission.

Table 2. Available Parameters to Evaluate Ventilator Over- and Underassist

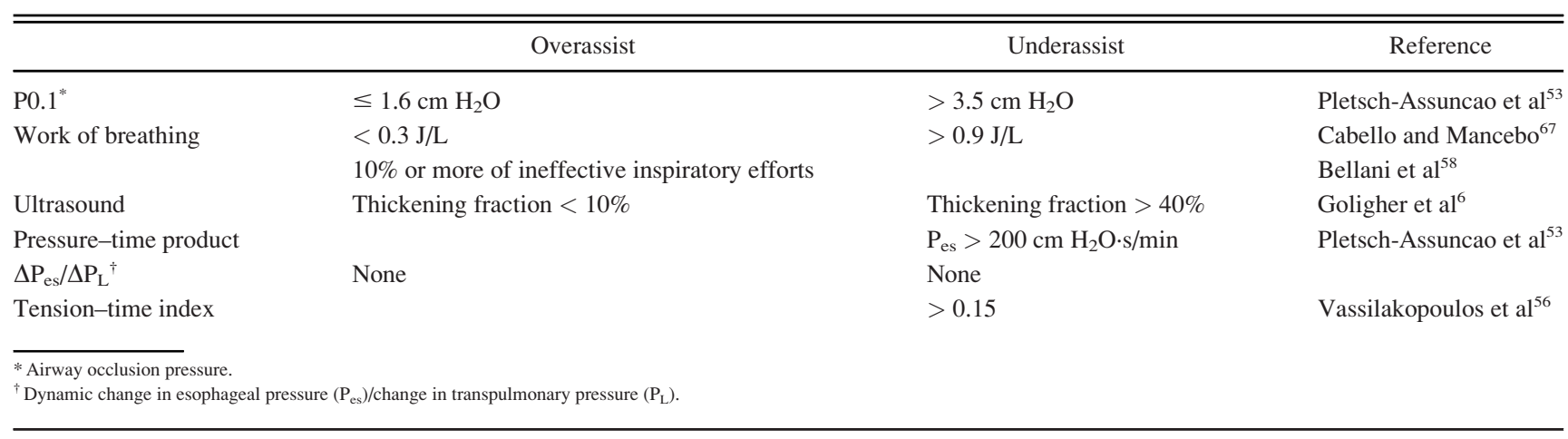

high or low respiratory effort. In addition to the effects on the diaphragm itself, inappropriate respiratory muscle effort is also associated with lung injury, patient-ventilator asynchrony, and poor sleep quality. Furthermore, recent evidence has indicated that diaphragm dysfunction by itself has a strong impact on patient outcome. As a consequence, the assessment of diaphragm function and activity during mechanical ventilation has gained importance in the ICU setting. Several methods are available, including pressure-based parameters, EMG, and ultrasound. Depending on their specific use, these methods can evaluate strength (ie, function) or measure activity. 


\section{Assessing Diaphragmatic Function}

Using these tools, the potential to balance diaphragm activity and to combine diaphragm- and lung-protective elements in a novel ventilation strategy has emerged. Future research will need to further detail these elements and define safe margins for diaphragm activity. For those reasons, a good understanding of monitoring tools is needed, and building expertise into at least one of them is useful for the bedside clinician.

\section{ACKNOWLEDGMENT}

We thank Jose Dianti MD, for his help in designing the figures.

\section{REFERENCES}

1. Dres M, Dubé B-P, Mayaux J, Delemazure J, Reuter D, Brochard L, et al. Coexistence and impact of limb muscle and diaphragm weakness at time of liberation from mechanical ventilation in medical intensive care unit patients. Am J Respir Crit Care Med 2017;195(1):57-66.

2. Hermans G, Agten A, Testelmans D, Decramer M, Gayan-Ramirez G. Increased duration of mechanical ventilation is associated with decreased diaphragmatic force: a prospective observational study. Crit Care 2010;14(4):R127.

3. Supinski GS, Callahan LA. Diaphragm weakness in mechanically ventilated critically ill patients. Crit Care 2013;17(3):R120

4. Kim WY, Suh HJ, Hong S-B, Koh Y, Lim C-M. Diaphragm dysfunction assessed by ultrasonography: Influence on weaning from mechanical ventilation. Crit Care Med 2011;39:2627-2630.

5. Medrinal C, Prieur G, Frenoy É, Quesada AR, Poncet A, Bonnevie T, et al. Respiratory weakness after mechanical ventilation is associated with one-year mortality: a prospective study. Crit Care 2016;20(1): 231.

6. Goligher EC, Dres M, Fan E, Rubenfeld GD, Scales DC, Herridge MS, et al. Mechanical ventilation-induced diaphragm atrophy strongly impacts clinical outcomes. Am J Respir Crit Care Med 2018;197 (2):204-213

7. Dres M, Goligher EC, Heunks LMA, Brochard LJ. Critical illnessassociated diaphragm weakness. Intensive Care Med 2017;43(10): 1441-1452.

8. Goligher EC, Brochard LJ, Reid WD, Fan E, Saarela O, Slutsky AS, et al. Diaphragmatic myotrauma: a mediator of prolonged ventilation and poor patient outcomes in acute respiratory failure. Lancet Respir Med 2019;7(1):90-98.

9. Brochard L. Ventilation-induced lung injury exists in spontaneously breathing patients with acute respiratory failure: yes. Intensive Care Med 2017;43(2):250-252.

10. Yoshida T, Nakahashi S, Nakamura MAM, Koyama Y, Roldan R, Torsani V, et al. Volume-controlled ventilation does not prevent injurious inflation during spontaneous effort. Am J Respir Crit Care Med 2017;196(5):590-601.

11. Marini JJ. Spontaneously regulated vs. controlled ventilation of acute lung injury/acute respiratory distress syndrome. Curr Opin Crit Care 2011;17(1):24-29.

12. Agostoni E, Rahn H. Abdominal and thoracic pressures at different lung volumes. J Appl Physiol 1960;15:1087-1092.

13. Hess DR. Respiratory mechanics in mechanically ventilated patients. Respir Care 2014;59(11):1773-1794.

14. Laporta D, Grassino A. Assessment of transdiaphragmatic pressure in humans. J Appl Physiol 1985;58(5):1469-1476.

15. Yoshida T, Amato MBP, Grieco DL, Chen L, Lima CAS, Roldan R, et al. Esophageal manometry and regional transpulmonary pressure in lung injury. Am J Respir Crit Care Med 2018;197(8):1018-1026.
16. Aliverti A, Cala SJ, Duranti R, Ferrigno G, Kenyon CM, Pedotti A, et al. Human respiratory muscle actions and control during exercise. J Appl Physiol 1997;83(4):1256-1269.

17. De Troyer A, Estenne M, Ninane V, Van Gansbeke D, Gorini M. Transversus abdominis muscle function in humans. J Appl Physiol 1990;68(3):1010-1016.

18. Finucane KE, Panizza JA, Singh B. Efficiency of the normal human diaphragm with hyperinflation. J Appl Physiol 2005;99(4):1402-1411.

19. Schepens T, Goligher EC. Lung- and diaphragm-protective ventilation in acute respiratory distress syndrome: rationale and challenges. Anesthesiology 2019;130(4):620-633.

20. Goligher EC, Fan E, Herridge MS, Murray A, Vorona S, Brace D, et al. Evolution of diaphragm thickness during mechanical ventilation: impact of inspiratory effort. Am J Respir Crit Care Med 2015;192 (9): 1080-1088.

21. Levine S, Nguyen T, Taylor N, Friscia ME, Budak MT, Rothenberg P, et al. Rapid disuse atrophy of diaphragm fibers in mechanically ventilated humans. N Engl J Med 2008;358(13):1327-1335.

22. Jaber S, Petrof BJ, Jung B, Chanques G, Berthet J-P, Rabuel C, et al. Rapidly progressive diaphragmatic weakness and injury during mechanical ventilation in humans. Am J Respir Crit Care Med 2011;183 (3):364-371.

23. Schepens T, Verbrugghe W, Dams K, Corthouts B, Parizel PM, Jorens PG. The course of diaphragm atrophy in ventilated patients assessed with ultrasound: a longitudinal cohort study. Crit Care 2015;19:422

24. Grosu HB, Lee YI, Lee J, Eden E, Eikermann M, Rose K. Diaphragm muscle thinning in patients who are mechanically ventilated. Chest 2012;142(6): 1455-1460

25. Gayan-Ramirez G, Testelmans D, Maes K, Rácz GZ, Cadot P, Zádor $\mathrm{E}$, et al. Intermittent spontaneous breathing protects the rat diaphragm from mechanical ventilation effects. Crit Care Med 2005;33:28042809.

26. Ahn B, Beaver T, Martin T, Hess P, Brumback BA, Ahmed S, et al. Phrenic nerve stimulation increases human diaphragm fiber force after cardiothoracic surgery. Am J Respir Crit Care Med 2014;190(7):837839.

27. Martin AD, Joseph A-M, Beaver TM, Smith BK, Martin TD, Berg K, et al. Effect of intermittent phrenic nerve stimulation during cardiothoracic surgery on mitochondrial respiration in the human diaphragm. Crit Care Med 2014;42:e152-e156.

28. Telias I, Brochard L, Goligher EC. Is my patient's respiratory drive (too) high? Intensive Care Med 2018;44(11):1936-1939.

29. Wang X, Jiang T-X, Road JD, Redenbach DM, Reid WD. Granulocytosis and increased adhesion molecules after resistive loading of the diaphragm. Eur Respir J 2005;26(5):786-794.

30. Vassilakopoulos T, Hussain S. Ventilatory muscle activation and inflammation: cytokines, reactive oxygen species, and nitric oxide. J Appl Physiol 2007;102(4):1687-1695.

31. Reid WD, Huang J, Bryson S, Walker DC, Belcastro AN. Diaphragm injury and myofibrillar structure induced by resistive loading. J Appl Physiol 1994;76(1):176-184.

32. Lin MC, Ebihara S, El Dwairi Q, Hussain SN, Yang L, Gottfried SB, et al. Diaphragm sarcolemmal injury is induced by sepsis and alleviated by nitric oxide synthase inhibition. Am J Respir Crit Care Med 1998;158(5 Pt 1):1656-1663.

33. Pellegrini M, Hedenstierna G, Roneus A, Segelsjö M, Larsson A, Perchiazzi G. The diaphragm acts as a brake during expiration to prevent lung collapse. Am J Respir Crit Care Med 2017;195(12):16081616.

34. Tobin MJ, Perez W, Guenther SM, Lodato RF, Dantzker DR. Does rib cage-abdominal paradox signify respiratory muscle fatigue? J Appl Physiol 1987;63(2):851-860.

35. Lindqvist J, van den Berg M, van der Pijl R, Hooijman PE, Beishuizen A, Elshof J, et al. Positive end-expiratory pressure ventilation induces 


\section{Assessing Diaphragmatic Function}

longitudinal atrophy in diaphragm fibers. Am J Respir Crit Care Med 2018;198(4):472-485.

36. Supinski GS, Kelsen SG. Effect of elastase-induced emphysema on the force-generating ability of the diaphragm. J Clin Invest 1982;70 (5):978-988.

37. Laveneziana P, Albuquerque A, Aliverti A, Babb T, Barreiro E, Dres $\mathrm{M}$, et al. ERS statement on respiratory muscle testing at rest and during exercise. Eur Respir J 2019;53(6): 1801214.

38. Steier J, Kaul S, Seymour J, Jolley C, Rafferty G, Man W, et al. The value of multiple tests of respiratory muscle strength. Thorax 2007;62 (11):975-980.

39. Demoule A, Jung B, Prodanovic H, Molinari N, Chanques G, Coirault $\mathrm{C}$, et al. Diaphragm dysfunction on admission to the intensive care unit. Prevalence, risk factors, and prognostic impact: a prospective study. Am J Respir Crit Care Med 2013;188(2):213-219.

40. Gottesman E, McCool FD. Ultrasound evaluation of the paralyzed diaphragm. Am J Respir Crit Care Med 1997;155(5):1570-1574.

41. Boussuges A, Gole Y, Blanc P. Diaphragmatic motion studied by Mmode ultrasonography. Methods, reproducibility, and normal values. Chest 2009; 135(2):391-400.

42. Cattapan SE, Laghi F, Tobin MJ. Can diaphragmatic contractility be assessed by airway twitch pressure in mechanically ventilated patients? Thorax 2003;58(1):58-62.

43. Watson AC, Hughes PD, Louise Harris M, Hart N, Ware RJ, Wendon $\mathrm{J}$, et al. Measurement of twitch transdiaphragmatic, esophageal, and endotracheal tube pressure with bilateral anterolateral magnetic phrenic nerve stimulation in patients in the intensive care unit. Crit Care Med 2001;29(7):1325-1331.

44. Dres M, Goligher EC, Dubé B-P, Morawiec E, Dangers L, Reuter D, et al. Diaphragm function and weaning from mechanical ventilation: an ultrasound and phrenic nerve stimulation clinical study. Ann Intensive Care 2018;8(1):53-57

45. Truwit JD, Marini JJ. Validation of a technique to assess maximal inspiratory pressure in poorly cooperative patients. Chest 1992;102 (4):1216-1219.

46. Piquilloud L, Beloncle F, Richard J-C, Mancebo J, Mercat A, Brochard L. Information conveyed by electrical diaphragmatic activity during unstressed, stressed and assisted spontaneous breathing: a physiological study. Ann Intensive Care 2019;9(1):89-14.

47. Telias I, Damiani F, Brochard L. The airway occlusion pressure (P0.1) to monitor respiratory drive during mechanical ventilation: increasing awareness of a not-so-new problem. Intensive Care Med 2018;44 (9):1532-1535.

48. Holle RH, Schoene RB, Pavlin EJ. Effect of respiratory muscle weakness on P0.1 induced by partial curarization. J Appl Physiol Respir Environ Exerc Physiol 1984;57(4):1150-1157.

49. Alberti A, Gallo F, Fongaro A, Valenti S, Rossi A. P0.1 is a useful parameter in setting the level of pressure support ventilation. Intensive Care Med 1995;21(7):547-553.

50. Mancebo J, Albaladejo P, Touchard D, Bak E, Subirana M, Lemaire $\mathrm{F}$, et al. Airway occlusion pressure to titrate positive end-expiratory pressure in patients with dynamic hyperinflation. Anesthesiology 2000;93:81-90.

51. Rittayamai N, Beloncle F, Goligher EC, Chen L, Mancebo J, Richard J-C, Brochard L. Effect of inspiratory synchronization during pressure-controlled ventilation on lung distension and inspiratory effort. Ann Intensive Care 2017;7:100-110.
52. Mauri T, Grasselli G, Suriano G, Eronia N, Spadaro S, Turrini C, et al. Control of respiratory drive and effort in extracorporeal membrane oxygenation patients recovering from severe acute respiratory distress syndrome. Anesthesiology 2016;125:159-167.

53. Pletsch-Assuncao R, Caleffi Pereira M, Ferreira JG, Cardenas LZ, de Albuquerque ALP, de Carvalho CRR, Caruso P. Accuracy of invasive and noninvasive parameters for diagnosing ventilatory overassistance during pressure support ventilation. Crit Care Med 2018;46(3):411417.

54. Field S, Kelly SM, Macklem PT. The oxygen cost of breathing in patients with cardiorespiratory disease. Am Rev Respir Dis 1982;126 (1):9-13

55. Bellemare F, Grassino A. Evaluation of human diaphragm fatigue. J Appl Physiol Respir Environ Exerc Physiol 1982;53(5):1196-1206.

56. Vassilakopoulos T, Zakynthinos S, Roussos C. The tension-time index and the frequency/tidal volume ratio are the major pathophysiologic determinants of weaning failure and success. Am J Respir Crit Care Med 1998;158(2):378-385.

57. Luo YM, Hart N, Mustfa N, Lyall RA, Polkey MI, Moxham J. Effect of diaphragm fatigue on neural respiratory drive. J Appl Physiol 2001;90(5):1691-1699.

58. Bellani G, Mauri T, Coppadoro A, Grasselli G, Patroniti N, Spadaro S, et al. Estimation of patient's inspiratory effort from the electrical activity of the diaphragm. Crit Care Med 2013;41:1483-1491.

59. Bellani G, Coppadoro A, Pozzi M, Bronco A, Albiero D, Eronia N, et al. The ratio of inspiratory pressure over electrical activity of the diaphragm remains stable during ICU stay and is not related to clinical outcome. Respir Care 2016;61(4):495-501.

60. Liu L, Liu H, Yang Y, Huang Y, Liu S, Beck J, et al. Neuroventilatory efficiency and extubation readiness in critically ill patients. Crit Care 2012;16(4):R143.

61. Matamis D, Soilemezi E, Tsagourias M, Akoumianaki E, Dimassi S, Boroli F, et al. Sonographic evaluation of the diaphragm in critically ill patients. Technique and clinical applications. Intensive Care Med 2013;39(5):801-810.

62. Goligher EC, Laghi F, Detsky ME, Farias P, Murray A, Brace D, et al. Measuring diaphragm thickness with ultrasound in mechanically ventilated patients: feasibility, reproducibility and validity. Intensive Care Med 2015;41(4):734

63. Schepens T, Dres M, Heunks L, Goligher EC. Diaphragm-protective mechanical ventilation. Curr Opin Crit Care 2019;25(1):77-85.

64. Vivier E, Mekontso Dessap A, Dimassi S, Vargas F, Lyazidi A, Thille AW, Brochard L. Diaphragm ultrasonography to estimate the work of breathing during non-invasive ventilation. Intensive Care Med 2012;38(5):796-803.

65. Dubé B-P, Dres M, Mayaux J, Demiri S, Similowski T, Demoule A. Ultrasound evaluation of diaphragm function in mechanically ventilated patients: comparison to phrenic stimulation and prognostic implications. Thorax 2017;72(9):811-818.

66. Zambon M, Greco M, Bocchino S, Cabrini L, Beccaria PF, Zangrillo A. Assessment of diaphragmatic dysfunction in the critically ill patient with ultrasound: a systematic review. Intensive Care Med 2017;43 (1):29-38

67. Cabello B, Mancebo J. Work of breathing. Intensive Care Med 2006; 32(9):1311-1314.

68. Schepens T, Goligher EC. Using ultrasound to prevent diaphragm dysfunction. ICU Manag Pract 2018;18(4):258-260.

\section{Discussion}

Pham: It's amazing work you've performed, and we use it a lot in our daily practice. I always struggle with the precision of the measurements because we're talking about something that's $2 \mathrm{~mm}$ and so whether you have a $20 \%$ variation, let's say it goes from 2 to $2.4 \mathrm{~mm}$ and sometimes the precision of your caliper is not that good. If you go just one pixel above or below you will have very different impressions. How do you take that into account when you measure, and 
how do you make sure that what you measure is what you see on the screen?

Goligher: An excellent point, Tài. In a lot of the early work we did looked at measuring ability and reproducibility with the technique, we found that you could get very good reproducibility of end-expiratory thickness measurements, the thickness of the muscle with reproducibility of \pm $0.2 \mathrm{~mm}$ when the technique was optimized. However, the reproducibility of the thickening fraction, because it's really the combination and ratio of 2 different thickness measurements (and therefore combines the error of both measurements) is suboptimal; $\pm 16-$ $20 \%$ is what we showed. There's no question that it's an imperfect technique for monitoring inspiratory effort from that standpoint, you're going to have noise. You'll be able to distinguish between a patient who's not making any effort, a patient making low effort like a healthy subject, a patient making elevated effort, and a patient making very high effort. But in terms of a change from $10 \%$ vs $20 \%$ I wouldn't call that physiologically significant just given the measurement noise. Nevertheless, this does a couple of things. First of all, it means the technique really starts to shine whenever you're able to make measurements in large groups of patients where the signal/noise ratio can become clearer. Really the exciting advance of the technique is that it allows you to assess the diaphragm in large numbers of patients because it's so feasible. Secondly, I think it's questionable whether this is the answer in terms of driving our monitoring of respiratory effort at the bedside. Should we be using thickening fraction to decide how much pressure support is best so that the patient is in the optimum window? Personally, I think it's not quite feasible enough, it takes 5-10 minutes to set up, you have to find the diaphragm, and until if and when somebody develops a probe that sits there continuously and can make measurements, I'm not sure it's sufficiently easy to implement, never mind the reproducibility. In my view, things like airway occlusion pressure or the occlusion pressure technique described here or EAdi or other pressure-based techniques for monitoring have a lot more potential to guide diaphragm-protective ventilation, but I'm still amazed by how much we've been able to learn from a technique that's not perfect.

Blanch: How important is the diaphragm condition at the beginning of mechanical ventilation in terms of injury. Should we use different protective mechanical ventilation strategies? Should we use more spontaneous breathing or less sedation?

Goligher: This is my personal bias, but I really think this should be considered in every patient who's on a ventilator, because in our cohort study subjects were at similar risk of diaphragm atrophy across the range of diagnoses whether it was acute hypoxemic respiratory failure or posttransplantation or all different admission diagnoses. I think it's something we need to consider with every ventilated patient, it's a little different than even lung protection, which primarily we think about in ARDS. Granted, we do think about lung protection in other patients. First, a diaphragm-protective approach should be considered in most patients. Second, in order to implement a diaphragm-protective approach, it's not going to just change how we set the ventilator, it's going to change how we apply sedation, it will change which sedatives we use, and so on. We actually just organized a consensus meeting in Milan with the Pleural Pressure Working Group to get together and think about all these kinds of issues because it's a completely different paradigm for how to manage respiratory failure. In terms of concerns about load-induced injury, the concerns about this apply even before the patient is intubated. How much load-induced injury are patients developing while we're sitting there trying to decide whether to intubate them and put them on a ventilator or not?

Blanch: This links with breathing frequency and effort. Before mechanical ventilation initiation, usually frequency changes little while effort increases.

Goligher: Exactly. That's a very important point. Frequency really doesn't reflect effort levels very well at all.

Smallwood: I think the future is interesting, so I'll be very attentive to where this work goes in topics connected to this conference. What Lluís [Blanch] was asking about, you have this information and you showed this great figure of 3 groups, those who had a thickening at the onset of mechanical ventilation, those that maintained that thickening, and those who lost thickness. I understand it's going to be a little bit speculative, but I'd be interested to hear your vision for what that's going to be at the bedside. One such case may be, 'hey this person has been dwindling on the floor because the clinician didn't count the frequency properly, missed signs of respiratory distress and this poor soul has been working like a dog... let's rest them for a period of time and allow their diaphragm to recover.' Or perhaps there's another group who will be susceptible to rapid onset diaphragmatic atrophy in the ICU. I'm interested to hear your thoughts as to where this may go.

Goligher: I think we need to do a huge amount of work to understand which patients we need to be most attentive to these issues in, and what 
the relative balance of protecting the lung versus protecting the diaphragm is because the two issues sometimes compete. Sometimes you have a completely suppressed respiratory effort in order to minimize tidal volume, and at that point you're sacrificing the diaphragm in order to protect the lungs. The timing of which organ you prioritize and when is an important issue that needs to get sorted out. I would say in general we should be targeting a relatively lownormal level of effort in all patients from the moment of intubation essentially. Whether or not that's feasible is a different question because there are sometimes reasons why respiratory effort needs to be suppressed. We're now running a pilot feasibility physiological trial where we're trying to take subjects at a very early stage and see if we can get their respiratory effort into a protective range. The idea would be really that everyone should be breathing at a low-normal level of effort as seen in healthy subjects unless there's some good reason why the case should be otherwise.

Rackley: What is the timeframe and magnitude of recovery?

Goligher: That's an interesting question that actually needs to be described. I've seen data from a group in Italy as well as some of our data, where some patients will recover diaphragm thickness almost as rapidly as they lost it and in others it seems to persist. There are so much data that we haven't had time to analyze and write it all up, but that's an important project waiting to happen. In animal models, the muscle can recover very quickly after the reinstitution of respiratory effort. It's probably not that big of a deal to have a patient apneic for a couple of days, but as soon as they're allowed to breathe we should try to make sure that the muscle is active at the protective level to try and restore function. But it's a great question that needs more study.

Rackley: If the recovery potential is so high, would that argue more for protecting the lungs over the diaphragm?

Goligher: I think so, for sure. There's no question that lung injury drives mortality, we know that from ARDSnet and other trials - I'm not claiming that diaphragm injury necessarily drives mortality. We've found a very weak association with mortality. However, patients may survive but then will be stuck on the ventilator for a prolonged period of time because of myotrauma and then develop other nosocomial badness from the prolonged mechanical ventilation and then experience the devastating functional sequelae of critical illness - in my view, intervening on myotrauma has the potential to change long-term functional outcomes. It may not change survival per se.

Blanch: The question is which is the worst asynchrony for diaphragm injury?

\section{Goligher: Ask Tài [Pham].}

Pham: I have no answer, ask Laurent Brochard.

Goligher: It's hard to answer confidently, but there are several ways in which asynchrony may be injurious to the diaphragm. And probably the most important way is by inducing eccentric contractions of the muscle, these are contractions that occur while the muscle is lengthening rather than shortening. Usually when you're using your diaphragm, the inspiring muscle is shortening and lung volume is increasing. But, for example, in reverse triggering the muscle often reaches peak contractile activity after the ventilator has already cycled into expiration, so lung volume is actually decreasing. The dome of the diaphragm is rising and then the diaphragm is forced to contract while it's rising and that induces eccentric contractile conditions. It's a well-established principle of exercise physiology that if you want to train a muscle you do so by injuring it and the best way to injure it is with an eccentric contraction, that's why when you lift weights to strengthen your biceps, you really want to contract that bicep as you're lowering the weight because that's where the injury stimulus for hypertrophy occurs. It's the same with the diaphragm. Of course because you're repeating it over for hours and hours it becomes very injurious rather than having a training effect. A similar circumstance we might be familiar with eccentric contraction is after a day of skiing and the next day your quads are screaming in pain, it's because you were having eccentric contractions in your quadriceps all day the day before. There are very limited experimental data showing that eccentric contractions are fairly injurious to the diaphragm. I'm aware of some data from a group in Toronto, who found it may be profoundly injurious to the diaphragm, but this needs to be studied more. The principle is that anything that causes an eccentric contraction, even short cycling where a patient is in the middle of an inspiratory effort and all of a sudden the ventilator stops delivering inspiratory support and the patient is stuck, that could be profoundly injurious as well.

Pham: On the subject of eccentric contraction, it is certainly injurious but beyond the type of asynchrony it's also the magnitude of the efforts that may be important. This reverse triggering, after passive insufflation depending on the timing might have a different impact. And if the peak is before inflation, maybe it will maintain your diaphragm function by having some 
contractions rather than remaining totally passive. But it's a hypothesis only; we have no proof.

Branson: I'm sure you've seen the idea of pacing the diaphragm. A lung pacer company has proposed a clinical trial (Percutaneous Temporary Placement of a Phrenic Nerve Stimulator for Diaphragm Pacing (RESCUE1) ClinicalTrials.gov Identifier: NCT03107949). What do you think about doing pacing of the diaphragm, regardless of the method by which you do it? To me it seems clear that pacing a diaphragm that has disuse atrophy is going to be completely different than pacing a diaphragm in a septic patient or a patient who has respiratory muscle weakness.

Goligher: Great question. There are certainly data that show that phrenic nerve stimulation in human subjects during cardiac surgery can protect mitochondrial function in the muscle, in the diaphragm for example. So there is a lot of biological plausibility for the technique. I think the question is in whom should we do this? It needs to be in a patient in whom you otherwise cannot optimize mechanical ventilation to achieve a reasonable respiratory effort level. It's somebody who will have to be heavily sedated for at least $24 \mathrm{~h}$ in order to be a patient who could benefit from the intervention. But also they can't be pharmacologically paralyzed because this kind of phrenic nerve pacing really doesn't achieve any effect. It's an ongoing question of exactly who is the most likely to benefit. In the group of patients with sepsis in whom the muscle becomes very vulnerable and fragile to mechanical stresses, you might well be doing more harm than good. You'd probably have to generate a high-normal level effort levels in order to achieve much injury, pacing at a low effort level might still be safe in these patients but that's an important subgroup that needs to be studied.

Blanch: My question is regarding ineffective efforts. In pressure support, excessive assistance is accompanied with ineffective inspiratory efforts but not dyspnea. The contrary happens in conditions of insufficient assistance where there are not ineffective efforts because respiratory drive is increased but at considerable dyspnea.
Goligher: I'm not sure how injurious ineffective efforts are because most of the time the effort levels during ineffective efforts are really quite small. I assume you agree with me on that?

Blanch: I agree.

Goligher: I think like Tài pointed out it's a dose-dependent phenomenon and if the effort levels are very small even if the contractile conditions are potentially injurious it's probably not that big of a deal.

Blanch: Maybe the point is comfort. Vitacca et $\mathrm{al}^{1}$ tested different levels of pressure support and PEEP showed a U shape relationship between excessive dyspnea without ineffective efforts and no dyspnea with increased hyperinflation and ineffective efforts. Perhaps a balance between the two is clinically acceptable.

\section{REFERENCE}

1. Vitacca M, Bianchi L, Zanotti E, Vianello A, Barbano L, Porta R, Clini E. Assessment of physiologic variables and subjective comfort under different levels of pressure support ventilation. Chest. 2004; 126(3):851-859. 